\title{
Ascorbic Acid Supplementation and Spermatogenesis in Nigerian Men
}

\author{
Maria O. Ebesunun*,a, Olayiwola. B. Shittu ${ }^{\mathrm{b}}$, Oluranti A Famooto ${ }^{\mathrm{b}}$, Emmanuel O. Agbedana ${ }^{\mathrm{c}}$ and \\ John I. Anetor ${ }^{\mathrm{c}}$ \\ ${ }^{a}$ Chemical Pathology, Obafemi Awolowo College of Health Sciences, Olabisi Onabanjo University, Sagamu Nigeria \\ ${ }^{b}$ Surgery Dept, College of Medicine University of Ibadan Nigeria, Nigeria \\ ${ }^{c}$ Chemical Pathology, College of Medicine University of Ibadan Nigeria, Nigeria
}

\begin{abstract}
Background: The role of ascorbic acid as an antioxidant nutrient in the maturation of sperm cells has received considerable attention. A previous study from our laboratory showed reduced seminal and plasma ascorbic acid in subfertile patients.

Method: Fifteen subfertile male patients mean age $36.4 \pm 0.9$ years with sperm counts of $31.4 \pm 7,08 \times 10^{6} / \mathrm{cm}^{3}$ were given $200 \mathrm{mg} /$ day dose of ascorbic acid as supplement for four weeks and ten highly fertile male mean age $35.6 \pm 1.7$ years with sperm count of $50.9 \pm 10.3 \times 10^{6} / \mathrm{cm}^{3}$ volunteers were selected as controls. The biochemical parameters and anthropometric measurements were determined using standard methods.

Result: Significant decreases were obtained in baseline sperm cell count $(\mathrm{p}<0.01)$, percentage $(\%)$ motility and \%vitality $(\mathrm{p}<0.01)$, and the $\%$ of morphologically normal sperm cells $(\mathrm{p}<0.01)$ in the subfertile compared with the controls. The baseline plasma and seminal ascorbic acid concentrations were significantly reduced $(\mathrm{p}<0.001)$. The post-supplementation sperm cell count $(\mathrm{p}<0.001), \%$ motility and \%vitality $(\mathrm{p}<0.01)$ were significantly increased compared with the baseline values.

Conclusion: The enhanced reversal of poor semen quality and semen ascorbic acid status with dietary supplementation of vitamin $\mathrm{C}$ in subfertile is a pointer to its positive role in the maintenance of sperm cell integrity. Further work is therefore required to elucidate our findings.
\end{abstract}

Keyword: Ascorbic acid, high density lipoprotein, cholesterol, semen, infertility subfertile.

\section{INTRODUCTION}

Infertility has been a major medical and social concern since the existence of man. Despite the enormous progress in science, the blame of infertility until recently has always been put on the woman. However, advances in the study of gonad/sperm cell function and dysfunction has led to an increasing understanding of the role in male infertility relationships. Male infertility is not a single entity but presents a variety of different pathogenetic mechanisms, which result primarily from low concentrations of sperm cells in semen (low sperm count), abnormal spermatozoa to abnormal sperm function [1]. Free radicals have been implicated in the aetiology of male infertility. Loss of sperm function has also been associated with excessive generation of reactive oxygen species (ROS) due to oxidative stress [1,2] Available reports indicate that spermatogenesis in human generate reactive oxygen species (ROS) which can initiate peroxidation of unsaturated fatty acids in the sperm plasma membrane [3]. The use of antioxidant nutrients such as ascorbic acid, vitamin $\mathrm{E}, \beta$-carotene, and trace elements $(\mathrm{Se}, \mathrm{Cu}, \mathrm{Zn}$, and $\mathrm{Mn}$ ) in the management of infertility has therefore attracted interest $[2,3]$. Reports have shown that ascorbic acid maintains

*Address correspondence to this author at the Chemical Pathology Olabisi Onabanjo University, College of Health Sciences Sagamu Nigeria; Tel: +234-8055307626; Fax: (234)-2-2413545; E-mail: onoebe@yahoo.com sperm cell membrane integrity by preventing oxidative damage to DNA [4]. In particular, ascorbic acid has been reported to be involved in the maintenance of sperm cell plasma membrane integrity $[1,4]$. In a recent study in this community, we demonstrated low levels of plasma and semen ascorbic acid in subfertile weakly fertile males [5]. The present study has therefore been designed to assess baseline and post supplementation plasma ascorbic acid levels, lipid and lipoprotein profiles as well as sperm cell qualities in weakly fertile males to determine whether ascorbic acid supplementation at a dose of $200 \mathrm{mg} /$ day will improve sperm cell qualities in this group of weakly fertile male Nigerians of reproductive age.

\section{MATERIALS AND METHODS}

\section{Subjects}

Fifteen (15) young male subjects with mean age of $36.4 \pm 1.0$ years diagnosed as subfertile weakly fertile based on medical history and laboratory findings on the seminal fluid analysis, were selected for this study. Ten (10) freely living male volunteers age matched with the subfertile weakly fertile, were included as controls. All subjects recruited for this study were free living and were on normal habitual diets during the period of study. Baseline blood and semen samples were collected from weakly fertile subjects and controls at the beginning of the study. Thereafter ascor- 
bic acid of $200 \mathrm{mg} /$ day was given to all the patients, only for a period of four weeks, after which blood sample was collected from the patients only. This study received ethical approval from the University of Ibadan/University College Hospital Ethical Review Committee. Written or oral Informed Consent was obtained from all participants.

\section{Anthropometric Measurement}

The body weight and height of all subjects were measured using standard procedures. The body mass index was calculated using Quetelet formula W $(\mathrm{kg}) / \mathrm{H}^{2}(\mathrm{~m})$ [6].

\section{Blood Sample Collection}

Blood samples were collected from the antecubital fossa with pyrogen free syringes and sterile needles with minimal stasis from both patients and control subjects into ethylene diamine tetra acetic acid (EDTA) bottles after an overnight fast (10-14 hours). The samples were immediately wrapped in black carbon paper and placed in an ice bag to prevent oxidation. After centrifugation, each separated plasma sample was divided into two aliquots. One aliquot was immediately analyzed for ascorbic acid, while the second aliquot was stored at $-20^{\circ} \mathrm{C}$ until analyzed for lipid and lipoprotein profiles.

\section{Semen Collection}

Semen samples were obtained from all subjects by masturbation into plain bottles after 3-5 days of abstinence from sexual relationship. These samples were also assayed for ascorbic acid and total cholesterol (TC), LDLC and HDLC. The $\%$ motility, \% vitality, \%morphological abnormality, viscosity, volume and sperm cell count were assessed using the method recommended by WHO [7].

\section{Analytical Methods}

The method of Aye kyaw [8] was used for the assay of plasma/semen ascorbic acid levels. Declaration of Helsinki and semen total, HDL cholesterol and triglyceride concentrations $[9,10]$.

The LDL cholesterol level was calculated using the formula of Friedwald et al. [11]. Semen sperm counts, volume, $\%$ motility, \% vitality and \% of sperm cells with morphological normal were obtained using WHO [7] recommended methods. Quality control samples were included in all assays.

\section{Statistical Analysis}

All results were subjected to statistical analysis using the SPSS package analysis. The results were expressed as mean \pm SE. Student t- test and analysis of variance (ANOVA) were employed for pairwise and group comparison, this was further subjected to Post Hoc Test. Differences were regarded as significant at $\mathrm{p}<0.05$. Pearson correlation coefficient was used to determine any relationship in the different parameters.

\section{RESULTS}

As shown in Fig. (1), the seminal characteristics at baseline showed remarkable improvement in all sperm quality characteristics after supplementation with $200 \mathrm{mg}$ /day ascorbic acid for four consecutive weeks.

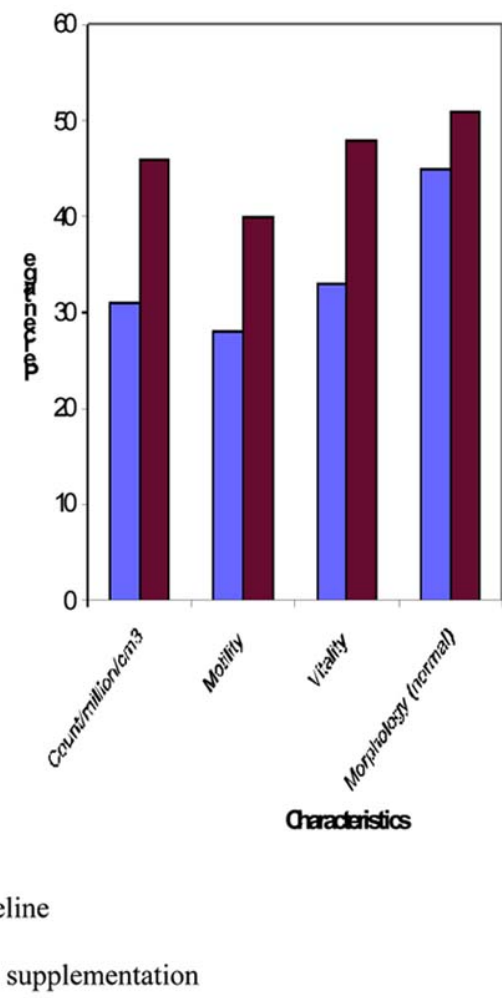

Fig. (1). Seminal characteristics at baseline and post supplementation.

Table 1 shows the physical characteristics and sperm cell quality of the subfertile patients at baseline and controls. The BMI in the subfertile men was significantly $(\mathrm{p}<0.05)$ higher in the patients than the corresponding control value. No significant differences were obtained in the other physical characteristics as well as the seminal volume. However, the sperm cell count $(\mathrm{p}<0.05), \%$ motility and $\%$ vitality $(\mathrm{p}<0.01)$ showed significant decreases when compared with the corresponding values in the control group. On the other hand the percentage morphology of normal cells $(\mathrm{p}<0.01)$ was significantly reduced in the subfertile men when compared with the corresponding value in the control group.

Table 2 shows biophysical and biochemical characteristics in subfertile men at baseline and post treatment. . These percentage increases in the sperm qualities in subfertile men from baseline and post supplementation in the seminal qualities are volume $(7.5 \%)$, \% sperm cell count (48\%), \%vitality $(45 \%)$, \% motility (43\%) and the \% morphology normal cells (14\%) from baseline values.

There were significant changes in the mean seminal HDLC and ascorbic acid $(\mathrm{p}<0.01)$ when compared with the corresponding baseline values. No significant changes were obtained in the other parameters.

Seminal fluid qualities $\&$ biochemical parameters of subfertile patients at baseline, post treatment and controls (Table 3). The analysis of variance showed significant changes in $\%$ motility and vitality $(\mathrm{p}<0.001)$. There were also significant increases in the seminal TG $(\mathrm{P}<0.05)$, HDLC $(\mathrm{P}<0.01)$ and ascorbic acid $(\mathrm{P}<0.001)$. The post Hoc analysis showed that there were significant increases in the \% motility, \%vitality, seminal HDLC, and ascorbic acid when compared with the control and baseline values. 
Table 1. Physical Characteristics and Sperm Qualities in Sub Fertile and Control SubjectS (Mean \pm S.E)

\begin{tabular}{|c|c|c|c|c|}
\hline & PATIENTS $(n=15)$ & CONTROLS $(n=10)$ & t-Value & p-Value \\
\hline AGE (yrs) & $36.5 \pm 5.36$ & $35.6 \pm 1.79$ & 0.51 & $>0.05$ \\
\hline HEIGHT (m) & $1.7 \pm 0.01$ & $1.7 \pm 0.02$ & 0.41 & $>0.05$ \\
\hline BMI $\left(\mathrm{kg} / \mathrm{m}^{2}\right)$ & $24.3 \pm 0.02$ & $22.6 \pm 0.09$ & 2.12 & $<0.05$ \\
\hline COUNT $\left(\times 10^{6} / \mathrm{cm}^{3}\right)$ & $31.4 \pm 7.08$ & $50.9 \pm 10.33$ & 2.71 & $<0.05$ \\
\hline MOTILITY (\%) & $28.6 \pm 4.66$ & $64.0 \pm 3.04$ & 2.90 & $<0.01$ \\
\hline VITALITY (\%) & $33.6 \pm 5.63$ & $63.5 \pm 3.4$ & 5.29 & $<0.01$ \\
\hline MORPHOLOGY (\%normality) & $46.4 \pm 8.04$ & $65.5 \pm 14.40$ & 6.50 & $<0.01$ \\
\hline
\end{tabular}

$\mathrm{BMI}=$ Body mass index

$\mathrm{n}=$ number of subjects.

$\mathrm{p}=$ significant level

Table 2. Physical Characteristics, Sperm Qualities and Biochemical Parameters in Subfertile Patients at Baseline and Post Supplementation $($ Mean \pm S.E)

\begin{tabular}{|c|c|c|c|c|}
\hline Variables & BASELINE $(n=15)$ & POST (n=15) & t-value & p- value \\
\hline & $68.41 \pm 1.95$ & $69.0 \pm 2.5$ & 0.144 & $>0.05$ \\
\hline HEIGHT (m) & $1.7 \pm 0.02$ & $1.7 \pm 0.02$ & 1.34 & $>0.05$ \\
\hline BMI $\left(\mathrm{kg} / \mathrm{m}^{2}\right)$ & $24.02 \pm 0.73$ & $24.4 \pm 1.27$ & 0.172 & $>0.05$ \\
\hline VOLUME $\left(\mathrm{cm}^{3}\right)$ & $2.8 \pm 0.40$ & $3.0 \pm 0.21$ & 0.332 & $>0.05$ \\
\hline COUNT (x 106 $\left./ \mathrm{cm}^{3}\right)$ & $31.4 \pm 7.08$ & $51.63 \pm 8.58$ & 3.081 & $<0.001 * * * *$ \\
\hline MOTILITY (\%) & $28.6 \pm 4.66$ & $40.0 \pm 4.80$ & 2.777 & $<0.01 * * *$ \\
\hline VITALITY (\%) & $33.6 \pm 5.63$ & $48.6 \pm 5.83$ & 2.469 & $<0.01 * * *$ \\
\hline \multirow[t]{2}{*}{ MORPHOLOGY (\%normal) } & $46.4 \pm 8.09$ & $51.3 \pm 5.50$ & 1.084 & $>0.05 * *$ \\
\hline & $75.4 \pm 9.50$ & $76.6 \pm 4.2$ & 1.513 & $>0.05$ \\
\hline \multirow[t]{2}{*}{$\mathrm{T} . \mathrm{G}(\mathrm{mg} / \mathrm{dl})$} & $70.4 \pm 5.58$ & $58.5 \pm 7.15$ & 1.86 & $>0.05$ \\
\hline & $22.7 \pm 1.9$ & $32.0 \pm 12.7$ & 2.30 & $<0.01$ \\
\hline LDLC (mg/dl) & $38.6 \pm 8.0$ & $25.3 \pm 7.6$ & 1.765 & $>0.05$ \\
\hline ASCORBIC ACID (mg/dl) & $1.8 \pm 0.28$ & $2.8 \pm 0.33$ & 2.39 & $<0.01$ \\
\hline
\end{tabular}

$\mathrm{n}=$ number of subjects $\mathrm{T} . \mathrm{C}=$ Total cholesterol.

TG = Triglyceride.

HDLC-=High density lipoprotein cholesterol.

LDLC $=$ Low density lipoprotein cholesterol.

$\mathrm{BMI}=$ Body mass index.

$* 7.5 \%$ increase from baseline value.

$* * 14 \%$.

$* * * 43-45 \%$.

$* * * * 68 \%$.

Table 4 shows plasma biochemical parameters in all subjects. The analysis of variance showed significant changes in plasma ascorbic acid concentration $(\mathrm{p}<0.001)$ and HDLC $(\mathrm{p}<0.01)$ only. The \%motility was significantly correlated with the \% of morphologically normal sperm cells only in the post supplementation $\quad(\mathrm{r}=0.646, \quad \mathrm{p}<0.01) \quad(\mathrm{r}=0.787$, $\mathrm{p}<0.01$ ) (table not shown).

\section{DISCUSSION}

This study appears to have significantly extended the earlier findings in our previous report in which plasma and seminal ascorbic acid levels were significantly reduced in subfertile male subjects at baseline [5]. 
Table 3. Seminal Fluid Qualities \& Biochemical Parameters of Subfertile Patients at Baseline, Post Treatment and Controls $($ Mean \pm S.E)

\begin{tabular}{|c|c|c|c|c|c|}
\hline Variable & Baseline $n=15$ & Post-Treatment $n=15$ & Control $n=10$ & F-value & p-value \\
\hline MOTILITY (\%) & $28.6 \pm 4.66$ & $40.2 \pm 4.8$ & $64.0 \pm 3.14$ & 13.59 & $<0.001$ \\
\hline VITALITY (\%) & $33.6 \pm 5.63$ & $48.0 \pm 5.83$ & $63.5 \pm 3.41$ & 9.086 & $<0.001$ \\
\hline T.C (mg/dl) & $75.4 \pm 9.50$ & $76.66 \pm 9.34$ & $57.0 \pm 4.20$ & 1.302 & $>0.05$ \\
\hline $\mathrm{TG}(\mathrm{mg} / \mathrm{dl})$ & $70.4 \pm 5.58$ & $58.66 . \pm 3.7$ & $54.5 \pm 7,1$ & 1.85 & $<0.05$ \\
\hline HDLC (mg/dl) & $22.73 \pm 1.9$ & $32.0 \pm 12.7$ & $26 . \pm 2.00$ & 5.060 & $<0.01$ \\
\hline LDLC (mg/dl) & $38.6 \pm 8.0$ & $25.3 \pm 7.6$ & $20.6 \pm 2.90$ & 1.337 & $>0.05$ \\
\hline
\end{tabular}

$\mathrm{n}=$ number of subjects.

T.C=Total cholesterol.

$\mathrm{TG}=$ Triglyceride.

HDLC-=High density lipoprotein cholesterol.

LDLC $=$ Low density lipoprotein cholesterol.

Table 4. Plasma Biochemical Parameters in Subfertile Men at Baseline, Post Supplementation and Control Subjects (mean \pm S.E)

\begin{tabular}{|c|c|c|c|c|c|}
\hline Variable & Baseline $n=15$ & Post-Treatment $n=15$ & Control $n=10$ & F-value & p-value \\
\hline $\mathrm{TC}(\mathrm{mg} / \mathrm{dl})$ & $168.3 \pm 16.81$ & $166.7 \pm 6.06$ & $165.1 \pm 10.3$ & 0.522 & $>0.05$ \\
\hline $\operatorname{HDLC}(\mathrm{mg} / \mathrm{dl})$ & $52.9 \pm 5.71$ & $64.2 \pm 5.6$ & $78.0 \pm 9.10$ & 3.311 & $<0.05$ \\
\hline LDLC (mg/dl) & $99.7 \pm 14.15$ & $88.9 \pm 13,53$ & $74.1 \pm 5.96$ & .0874 & $>0.05$ \\
\hline
\end{tabular}

$\mathrm{n}=$ number of subjects.

T.C=Total cholesterol.

$\mathrm{TG}=$ Triglyceride.

HDLC-=High density lipoprotein cholesterol

LDLC $=$ Low density lipoprotein cholesterol.

The sperm qualities and ascorbic acid status of the weakly fertile men prior to daily intake of ascorbic acid (200 mg) were generally poor as compared to the fertile men. There was clear evidence for a favorable response to ascorbic acid supplementation as our results showed remarkable improvement in sperm cell qualities as demonstrated by increases in sperm cell count, \% sperm cell motility, \% sperm cell vitality, and a reduction in the \% of sperm cell with abnormal morphology after ascorbic acid supplementation for four weeks. The plasma ascorbic acid was remarkably increased after supplementation, invariably leading to an increase in the concentration of ascorbic acid in the semen which probably caused a significant enhancement of spermatogenesis in these subjects. The significantly increased seminal ascorbic acid concentration probably suggests that improved sperm cell qualities after supplementation, may be mediated through increased availability of seminal ascorbic acid required for reducing the damaging effect of ROS in part and enhancement of spermatogenesis. Although a trend for improved semen parameters was observed after ascorbic acid supplementation, the difference was not statistically significant. Perhaps the improvement in the seminal qualities would have been more remarkable if the duration of supplementation was prolonged.

Previous studies have shown that high concentrations of ascorbic acid in the semen play an essential role in the maintenance of the genetic integrity of the sperm cell membrane [12-15]. In our subfertile men, the low density lipoprotein cholesterol, although not statistically significant was higher in the at baseline than in the controls. The resultant increased oxidation of LDLC to produce a high concentration of lipid peroxides $(\mathrm{COSH})$ may promote the destruction of sperm cell membrane and cause eventual death of sperm cell [13]. This speculation is corroborated by decreased level of LDLC, increased seminal concentrations of HDLC and ascorbic acid concentrations after four weeks of ascorbic acid supplementation in the subfertile men. It is also known that in the presence of adequate anti-oxidant nutrients, to scavenge injurious free radicals, the life span of sperm cells 
is normalized [15-20]. Our results suggest that ascorbate may play an essential positive role in spermatogenesis by its anti-oxidant properties and possible effect on ATP level in the seminal fluid.

From these results, it could be speculated that an important dietary determinant of male infertility in this community is low ascorbic acid status.

The enhanced reversal of poor semen qualities and semen ascorbic acid status when ascorbic acid was used as a dietary supplement in subfertile men for four weeks is consistent with a possible positive role of ascorbic acid in the maintenance of sperm cell integrity.

It is novel that simple and inexpensive ascorbic acid supplementation regimen could enhance fertility in male individuals. However, further work to include long-term effects of ascorbic acid supplementation in human subjects would shed more light on the important role that ascorbic acid can play in male fertility.

\section{ACKNOWLEDGEMENT}

We wish to acknowledge the staff of Surgical Research Laboratory for all the technical assistance.

\section{REFERENCES}

Aitkin, S.; Clarkson, J. Cellular basis of defective sperm function and its association with the genesis of reactive oxygen species. $J$. Reprod. Fertil., 1987, 81, 457.

Alvarez, J.; Story, B. Role of glutathione periods in protecting mammalian spermatozoa from loss of motility caused by spontaneous lipid per oxidation. Gamete Res., 1989, 23, 77.

Diplock, A.T. Antioxidant nutrients and disease prevention: an overview. Am. Clin. Nutr., 1991, 53, 1895-1935.

Gonzale, E.R. Sperm swims singly after vitamin C therapy. JAMA, 1983, 249, 2747-2751.

Ebesunun, M.O.; Sholademi, B.A.; Shittu, O.B.; Anetor, J.I.; Onuegbu, A.J.; Olisekodiaka, M.J.; Onyeaghala, A.A.; Agbedana, E.O. Plasma and semen ascorbic acid level in spermatogenesis. West Afr. J. Med., 2005, 23, 4 .

Rowland, M.L. A nomogram for computing body mass index. Dietetic. Curr., 1989, 16, 5-12.
World Health Organizations. Laboratory evaluation manual for serum examination of human semen and cervical-mucus interaction. Cambridge University Press: UK, 1967, p. 67.

[8] Kyaw, A. A simple colorimetric method for ascorbic acid determination in blood plasma. Clin. Chem. Acta, 1978, 86, 103-129.

[9] Allain, C.C.; Poon, L.S; Chan, C.S.G. Enzymatic determination of serum cholesterol. Clin. Chem., 1974, 20, 470-475.

[10] Buccolo, G.; David, H. Quantitative determination of serum triglycerides by the use of enzymes. Clin. Chem., 1973, 19, 476482.

[11] Friedwald, T.W.; Fredrickson, D.S.; Levy, R.J. LDL cholesterol estimation. Clin. Chem., 1972, 189, 499-501.

[12] Dawson, E.B.; Harris,W.A.; Teter, M.C.; Powell, L.C. Effect of ascorbic acid supplementation on the sperm quality of smokers. Fert. Steril., 1992, 58, 1034-1039.

[13] Grizard, G.; Sion, B.; Jouanel, P.; Benoit, P.; Boucher, D. Cholesterol, phospholipids and markers of the function of the accessory sex glands in the semen of men with hypercholesterolemia. Int. J. Androl., 1995, 18, 151-156.

[14] Irvine, D.S. Glutathione as a treatment for male infertility. Rev. Reprod., 1996, 1, 6-12.

[15] Ciereszko, A.; Dabrowski, K. Sperm quality and ascorbic acid concentration in rainbow trout semen are affected by dietary vitamin C: an across-season study. Biol. Reprod., 1995, 52, 982-988.

[16] Ciereszko, A.; Dabrowski, K.; Lin, F.; Liu, L. Protective role of ascorbic acid against damage to male germ cells in rainbow trout. (Oncorhynchus mykiss) Can. J. Fish Aquat. Sci., 1999, 56(2), 178183. (Abstract).

[17] Rolf, C.; Cooper, T.G.; Yeung, C.H.; Nieschlag, E. Antioxidant treatment of patients with asthenozoospermia or moderate oligoasthenozoospermia with high-dose vitamin $\mathrm{C}$ and vitamin $\mathrm{E}$ : a randomized, placebo-controlled, double-blind study. Hum. Reprod. 1999, 14(4), 1028-1033.

[18] Akmal, M.; Qadri, J.Q.; Al-Waili, N.S.; Thangal, S.; Haq, A.; Saloom, K.Y. Improvement in human semen quality after oral supplementation of vitamin C. J. Med. Food, 2006, 9(3),440-442.

[19] Gambera, L.; Campanella, G.; Piomboni, P.; Serafini, F.; Morgante, G.; De Leo, V. Association of antioxidants and natural immune activators in the treatment of astheno-teratospermia and abacterial leukocytosis. Minerva Ginecol., 2007, 59(5), 473-479.

[20] Piomboni, P.; Gambera, L.; Francesca, S.; Morgante, G.; De Leo, V. Sperm quality improvement after natural anti-oxidant treatment of asthenoteratospermic men with leukocytospermia. Asian. J. Androl., 2007, 10(2), 201-206.

(C) Ebesunun et al.; Licensee Bentham Open.

This is an open access article licensed under the terms of the Creative Commons Attribution Non-Commercial License (http://creativecommons.org/licenses/by-nc/3.0/) which permits unrestricted, non-commercial use, distribution and reproduction in any medium, provided the work is properly cited. 